\title{
KESINAMBUNGAN PANGGILAN MISIONARIS BANGSA ISRAEL DENGAN PANGGILAN PELAYANAN MISI DAN PEMURIDAN
}

\author{
Noh Ibrahim Boiliu
}

\author{
ABSTRAK
}

Tulisan ini bertujuan membahas kesinambungan panggilan misi bangsa Israel dengan panggilanpelayanan misi dan pemuridan. Misi dan pemuridan tidak boleh dipisabkan atau hanya menekankan salah satu. Di dalam misi harus ada pemuridan sebagai proses mendidik orang mengenal Tuban. Sedangkan pemuridan sebagai reaksi dan respons orang yang mengenal Tuban yang pada akbirnya dinyatakan dalam tindakan bermisi.

Kata Kunci: Panggilan Misi, Pelayanan Misi, Pemuridan

\section{PENDAHULUAN}

\section{Problematika}

Misi dan pemuridan merupakan hal yang tidak terpisahkan dalam tugas pelayanan gereja. Sejak Perjanjian Lama, tugas misi telah ada dan dapat dilihat dari sudut pandang panggilan dan pengutusan Israel. Israel di panggil sebagai bangsa yang mengemban tugas menyatakan Allah kepada bangsa-bangsa lain. Sedangkan pemuridan, dalam konteks Perjanjian Lama harus dilihat sebagai proses keberlanjutan dari misi. Panggilan Allah atas Israel berkaitan dengan pemuridan (praksis pendidikan) dapat dilihat dalam perealisasian panggilan Allah atas bangsa Israel untuk hanya menyembah satu Allah, Allah yang Esa seperti yang ada dalam Ulangan 6:4.

Pemuridan merupakan proses pendidikan (agama) yang bersumber dari Allah dan ditugaskan kepada Israel (PL: Allah kepada Israel), muridmurid Tuhan Yesus dan gereja (PB: Kristus kepada para rasul-Na dan 
kepada gereja sebagai tubuh-Nya). Dalam Perjanjian Lama, sumber epistemolognya bersumber dari Allah di mana Allah sebagai hakikat pendidikan yang mana persoalan moralitas menjadi dasar dari pengajaran dimaksud. Dengan hanya merujuk kepada Allah, maka Allah menjadi rujukan sumber moral. Dengan demikian, misi bermuara kepada pemuridan dan pemuridan kepada misi. Tidak ada misi yang meniadakan pemuridan sebagai proses mendidik umat mengenal Tuhan secara pribadi dan mendalam yang pada akhirnya menyatakan kembali pribadi Tuhan kepada yang lain.

Dalam segi ini, gereja tidak boleh hanya menekankan misi dan meniadakan pemuridan atau menekankan pemuridan dan meniadakan misi atau tidak menekankan kedua-duanya. Gereja di panggil untuk tugas misi, seperti Allah memanggil Israel dan Kristus memilih para rasul dan membentuk gereja sebagai tubuh-Nya serta mengejawentahkan tugas misi dan pemuridan kepada para rasul dan gereja.

\section{Pembahasan}

Memahami posisi bangsa Israel dalam peta visi Allah atas dunia merupakan sebuah pintu masuk untuk memahami kehendak Allah atas gereja. Urgensitas pemahaman kita atas posisi Israel dalam peta visi Allah adalah agar gereja Tuhan mengerti maksud pemanggilan, penetapan dan pengutusan Tuhan atas Israel; mengerti reaksi dan aksi Israel dalam menjalani misi tersebut. Memahami panggilan Allah atas Israel merupakan langkah awal dalam memahami peta misi Allah sebab "from Genesis to Malachi Jehovah is portrayed as a missionary God. The Jesus of the New Testament is the Jehovah of the Old. He was the first and great Missionary..." Perintah misi berkaitan dengan bagaimana manusia tetap berada di dalam hubungan dan komunikasi dengan Allah. Allah memanggil Israel dan nantinya gereja, adalah agar yang terputus hubungannya dengan

${ }^{1}$ J. Herbert Kane, The Christian World Mission. Today and Tomorrow (Michigan: Baker Book House Company, 1986),16 
Allah dapat mendengar berita misi dan kembali membangun hubungan dengan Allah sebab sejak awal, Allah menciptakan manusia untuk diriNya. "Man was created in the beginning not only by God but for God". ${ }^{2}$

Menurut Kane ada tiga tujuan pilihan Allah atas Israel saat kita melihatnya dalam konteks misi, yakni "first, Israel was to be the recipient and guardian of God's special revelation to the world (Heb. 1:1-3). Second, Israel was to be the channel through which the Redeemer was to enter the stream of human history. Third, Israel was to be God's servent and witness in the midst of the nations". ${ }^{3}$ Tujuan ini, oleh Harold Cook, ${ }^{4}$ juga berkaitan dengan sepuluh hukum Allah (the ten commandments) sebagai bukti legal (legalitas itu dapat dilihat melalui adanya tempat diberikan dan 10 hukum itu sendiri) bahwa Allah telah memilih dan mengutus mereka bahkan Allah pernah berbicara kepada mereka

Ketika Israel menerima panggilan tersebut melalui Musa, Israel pada umumnya pada waktu masih berada di Mesir, mereka hanya mengarahkan pandangannya pada bagaimana memeroleh kemerdekaan dari Mesir. Atau pun ketika Musa menyampaikan visi Tuhan atas mereka tentang Kanaan sebagai tujuan akhir mereka, mereka hanya mengerti berita tersebut sebatas "bebas dan memiliki negeri". Pandangan semacam ini tentu akan mengarahkan mereka hanya sebatas memiliki negeri sendiri, sehingga mereka menjadi setingkat dengan bangsa-bangsa lain di sekitarnya.

Pemikiran yang diungkapkan di atas dapat ditelusuri dari sikap dan reaksi dari Israel ketika Musa menyampaikan visi tersebut pertama kalinya bahkan sikap dan reaksi lainnya dapat ditelusuri ketika proses keluar dari Mesir, memasuki Kanaan dan menetap di Kanaan.

\section{Ibid}

3 Ibid, p. 27.

${ }^{4}$ Harold R. Cook, An Introduction to Christian Missions (USA: Moody Press, 1974), 61. Cook juga mengatakan bahwa, misi dapat ditemukan dalam Pentateukh (h. 59), Mazmur (p. 61), dan nabi-nabi (h. 62) 
Sikap dan reaksi umum yang dapat dijumpai adalah menafikan panggilan Allah atas mereka sebagai misionaris. Penafikan tersebut dapat dilihat dari sikap mereka untuk tidak terpaut kepada Tuhan, tegar tengkuk, dan lain-lain. Sikap-sikap ini menunjukkan bahwa mereka tidak memiliki tanggungjawab misi atau tidak melihat posisi mereka sebagai misionaris Tuhan di tengah-tengah bangsa kafir.

Berkaitan dengan mandat misi Allah kepada Israel, maka kita dapat mengerti konsep misi. Konsepnya adalah setiap orang yang belum mengenal Allah baik dalam konteks Perjanjian Lama maupun Perjanjian Baru harus mengenalnya melalui Israel (PL) dan melalui gereja Tuhan (PB). Wilayahnya meliputi seluruh dunia yakni yang belum mengenal dan menerima Tuhan (Kristus).

Israel dalam Perjanjian Lama dan gereja di Perjanjian Baru, samasama mengemban tugas sebagai misionaris. Ini berarti bahwa mereka harus melaksanakan mandat. Dalam konteks Perjanjian Lama, tidak ada keharusan untuk menjadi warga Israel sebagai representasi berada di dalam "Tuhan". Melainkan menunjukkan melalui sikap tunduk dan menyembah hanya kepada YHWH. Sedangkan di Perjanjian Baru, memang tidak ada keharusan untuk berada di dalam gereja namun tidak mungkin mengenal Allah dan menandainya jika tidak di dalam gereja. Ini berarti bahwa tidak ada jaminan bahwa yang berada di dalam gereja "pasti selamat", sejalan dengan itu juga tidak mungkin ada jaminan pengajaran yang benar jika tidak "di dalam gereja".

Dengan demikian, dalam hal ini menjadi konsentrasi dari tulisan singkat ini. Bahwa, misi bukanlah tugas pertama dan terakhir melainkan misi ada di dalam proses menjadi milik Kristus seutuhnya. Yakni, yang telah mengenal Allah (Kristus, baik PL maupun PB) di pundaknya tugas misi diletakan. Ini berarti semua orang percaya adalah misionaris. Proses selanjutnya adalah menjadikan semua murid Kristus, yakni yang telah mengenal dan menerima Kristus. 


\section{Tinjauan Umum Misi dalam Perjanjian Lama}

Ada kesalahpahaman yang populer bahwa Perjanjian Lama (PL) tidak memiliki suatu mandat misi dan bahwa PL adalah sebuah kitab yang didedikasikan hanya bagi orang Yahudi dan sejarah Yahudi. Akan tetapi, pandangan tersebut tidak sesuai dengan klaim yang dibuat oleh Perjanjian Lama itu sendiri. Bahkan jika membatasi penyelidikan kita kepada tiga teks kunci dalam Perjanjian Lama, kita akan langsung dapat melihat bahwa ketiga teks ini menghadirkan beberapa pernyataan panggilan misi yang paling kuat yang bisa ditemukan di mana pun di Alkitab.

Jika kita memerhatikan dengan saksama permulaan dari Perjanjian Lama maka kita akan lebih lambat menilai bahwa Perjanjian Lama tidak memiliki tantangan misi. Pesan dalam pasal-pasal terawal Kitab Kejadian adalah universal ruang lingkupnya dan global audiensnya. Bukankah Allah berurusan dengan "semua kaum di muka bumi" ketika Allah bertindak dalam anugerah yang menyelamatkan di ketiga titik penghubung spesifik dalam Kejadian 1-11? Sejak kejatuhan manusia, air bah di bumi dan kegagalan Menara Babel, Allah mengarahkan pesan agung mengenai keselamatan kepada seluruh umat manusia (Kej. 3:15; 9:17; 12:1-3). Bavink mengatakan bahwa "Genesis 1:3 and Genesis 10, as well as Paul's statement that God 'hath made of one blood all nations of men for to dwell on all the face of the earth' (Acts 17:26), have therefore an outstanding significance on the mission field". ${ }^{5}$

Dan jika meragukan bahwa janji Allah kepada Abraham (Kej. 12:1 3) adalah global ruang lingkupnya dan universal dalam penawarannya, kita harus memerhatikan bahwa "bangsa-bangsa" yang terpencar di seluruh bumi muncul di Kejadian 10, di dalam apa yang sering disebut "Tabel Tujuh Puluh Bangsa." Daftar seluruh bangsa, bahasa dan kaum merupakan latar belakang bagi janji Allah untuk memberkati "semua

${ }^{5}$ J.H. Bavink, An Introduction to the Science of Missions, New Jersey: P\&R Publishing, n.d, p. 13 
kaum di seluruh bumi” dalam Kejadian 12:3.

Ada tiga teks dasar yang bisa menjelaskan mandat misi yang telah Allah rancang bagi seluruh bangsa Israel: Kejadian 12:1-3, Keluaran 19:4-6, dan Mazmur 67. Perjanjian Lama tidak mungkin dimengerti secara akurat tanpa menyelidiki ketiga teks ini dalam konteks misinya. Di dalam rencana dan tujuan Allah, Israel selalu bertanggung jawab untuk mengomunikasikan pesan anugerah Allah kepada bangsa-bangsa. Bangsa Israel dimaksudkan untuk menjadi suatu bangsa pemberita.

Agar tidak berpikir bahwa ketiga teks Perjanjian Lama ini memberi mandat hanya kepada orang-orang pada masa itu saja, sehingga sama sekali tidak relevan bagi orang percaya pada masa kini, maka perlu dijelaskan bahwa ketiga teks tersebut juga merupakan panggilan Allah bagi orang percaya pada masa kini:

1. Memberitakan Rencana Allah untuk Memberkati Bangsa-bangsa (Kej. 12:3).

2. Berpartisipasi dalam Keimamatan Allah sebagai Agen-Agen dari Berkat itu (Kel. 19:4-6).

3. Membuktikan Maksud Allah untuk Memberkati Semua Bangsa (Mzm. 67).

Tidak seorang pun bisa berkata bahwa Perjanjian Lama dimulai secara etnosentris atau Allah dalam Perjanjian Lama begitu pro Yahudi, sehingga penjangkauan misi tidak terjadi sampai pada masa bangsabangsa bukan Yahudi. Kejadian 1-11 dengan jelas membuktikan hal yang sebaliknya. Ruang lingkup dari pasal-pasal ini adalah seluruh dunia dalam hal tawaran keselamatan bagi semua orang yang mau percaya. Tema yang bertentangan dalam pasal-pasal yang sama ini adalah usaha bangsabangsa untuk mencari "nama" bagi diri mereka sendiri. Baik Kejadian 6:4 maupun Kejadian 11:4, tujuan tunggal dari umat manusia adalah mendapatkan "nama" bagi diri mereka dan memajukan reputasi mereka sendiri - dengan mengorbankan "nama" Allah. 
Perkataan anugerah ketigalah yang relevan di sini karena menekankan anugerah Allah mengatasi kegagalan manusia dan usaha sesat mereka untuk mendapatkan "nama" atau reputasi bagi diri mereka sendiri. Lima kali Allah berkata, "Aku akan memberkati engkau," "Aku akan memberkati orang-orang yang memberkati engkau," dan "olehmu semua kaum di muka bumi akan mendapat berkat." Meski demikian, pemilihan (boleh dilihat sebagai suatu anugerah) Israel tidak serta merta membuat mereka "besar kepala."

"If Jehovah is the God of Israel because he has made a covenant with Israel, it is conceivable that other nations will also some day be included in that covenant. For Israel has no individual and peculiar claim upon God;m its privileged position is due solely tod God's electing grade. Israel is not better than other nation". ${ }^{6}$

Israel boleh merasakan pemilihan tersebut secara sendiri dalam konteks kesejarahan pemilihan dalam perjanjian (covenan) namun bergerak maju dan menjadi bagian semua bangsa yang mau mengenal Allah. Kata kuncinya adalah memberkati atau berkat. Kata yang sama ini menandai seluruh bagian ini, dimulai dengan perkataan kepada Adam dan Hawa: "Dia memberkati mereka dan berkata, "Beranakcuculah dan bertambah-tambah banyak," sama seperti Dia juga dengan murah hati berjanji untuk memberkati binatang-binatang.

Bangsa-bangsa akan diberkati melalui "keturunan" orang ini, merujuk kepada keturunan-keturunannya. "Sesungguhnya, keturunan" perempuan (Kej. 3:15), "keturunan" Sem di kemah di mana Tuhan mau datang dan berdiam (Kej. 9:27) dan "keturunan" Abraham semua membentuk suatu keutuhan kolektif. Entitas kolektif ini ditandai oleh serangkaian perwakilan yang berperan sebagai jaminan di muka untuk berkat tersebut sampai Kristus sendiri muncul dari garis keturunan yang sama sebagai bagian dari rangkaian dan entitas korporat tersebut.

${ }^{6}$ Ibid, p. 14 


\section{Tinjauan Umum Misi dalam Perjanjian Baru}

Para pujangga dan filsuf Yunani kuno merindukan suatu masyarakat ideal dan memimpikan suatu Zaman Keemasan yang hilang di masa lampau. Tetapi mereka tidak melihat kecemerlangan pada masa kini atau pengharapan bahwa masa depan seperti itu dapat terjadi. Iman IbraniKristen menyatakan pengharapannya dalam istilah Kerajaan Allah. Pengharapan alkitabiah ini tidak seperti mimpi para pujangga Yunani.

Sebaliknya pengharapan ini dinyatakan oleh Allah dan berakhir dalam Dia. Ide alkitabiah tentang Kerajaan Allah berakar secara mendalam pada Perjanjian Lama. Ide tersebut didasarkan pada keyakinan bahwa ada satu Allah yang kekal dan hidup yang telah menyatakan DiriNya kepada manusia. Allah tersebut juga telah menyatakan bahwa Dia memiliki tujuan bagi umat manusia yang telah dipilih-Nya untuk dicapai melalui Israel. Maka para nabi mengabarkan suatu hari ketika manusia akan hidup bersama dalam damai. Allah kemudian akan menjadi hakim antara bangsa-bangsa dan akan menjadi wasit bagi banyak suku bangsa; maka mereka akan menempa pedang-pedangnya menjadi mata bajak dan tombak-tombaknya menjadi pisau pemangkas; bangsa tidak akan lagi mengangkat pedang terhadap bangsa, dan mereka tidak akan lagi belajar perang (Yes. 2:4).

Masalah yang ada dalam masyarakat tidak hanya akan diselesaikan, tetapi kejahatan dalam lingkungan fisik manusia juga tidak akan ada lagi. Serigala akan tinggal bersama domba dan macan tutul akan berbaring di samping kambing. Anak lembu dan anak singa akan makan rumput bersama-sama, dan seorang anak kecil akan menggiringnya (Yes. 11:6).

Damai, keamanan, kenyamanan - semuanya dijanjikan di masa depan.Kemudian datanglah Yesus dari Nazaret dengan pengumuman ini, "Bertobatlah, sebab Kerajaan Sorga sudah dekat!" (Mat. 4:17). Tema kedatangan Kerajaan Allah ini sentral dalam misi-Nya. Pengajaran-Nya dibuat untuk menunjukkan kepada manusia bagaimana mereka bisa 
masuk ke dalam Kerajaan Allah (Mat. 5:20; 7:21). Pekerjaan Allah yang hebat dimaksudkan untuk membuktikan bahwa Kerajaan Allah telah datang ke atas mereka (Mat. 12:28). Berbagai perumpamaan Kristus mengilustrasikan kepada para murid-Nya kebenaran tentang Kerajaan Allah (Mat. 13:11). Ketika Dia mengajarkan para pengikut-Nya untuk berdoa, pada inti permohonan mereka ada kalimat, "datanglah Kerajaan$\mathrm{Mu}$, jadilah kehendak-Mu di bumi seperti di sorga" (Mat. 6:10). Menjelang kematian-Nya, Dia meyakinkan para murid-Nya bahwa Dia akan memberikan kebahagiaan pada mereka dan persekutuan dari kerajaan Allah (Luk. 22:22-30). Dia berjanji bahwa Dia akan datang kembali ke bumi dalam kemuliaan untuk membawa berkat-berkat Kerajaan Allah bagi mereka yang sejak semula semua itu telah disediakan (Mat. 25:31, 34).

Ketika kita berbicara tetang misi dan Perjanjian Baru, ${ }^{7}$ keduanya saling berkaitan. Dengan kata lain Perjanjian Baru tidak dapat dilepaskan dan dari tindakan misi. Ini berarti orang percaya tidak dapat dilepaskan dari misi. Bahkan, "Christianity, if it is real Christianity, must of necessity be missionary...it is strange until we realize that many people's ideas Christianity have only a remote connection with the New Testament". ${ }^{8}$ Kekristenan, misi dan pemuridan saling berkaitan.

Bahkan Perjanjian Baru merupakan kelanjutan misi Allah. Allah memanggil Israel ke Kanaan karena Allah mempunyai tujuan atas Israel. Allah menetapkan Kanaan sebagai tujuan akhir perjalanan Israel. Mereka diizinkan memiliki Kanaan bukan hanya untuk ditempati melainkan menempatinya dan menjadikan diri serta bangsa mereka sebagai rule model dalam iman kepada Allah. Ini berarti ada unsur kerugma atau unsur pemberitaan atau memberi kesaksian kepada bangsa lain yang belum mengenal Allah.

\footnotetext{
${ }^{7}$ Cook, Christian Mission, ibid. p. 31-58

${ }^{8}$ Ibid, p. 19
} 


\section{Hubungan Mandat Misi dengan Pemuridan}

Tidak ada seorang pun yang dapat menafikan hubungan misi dengan pemuridan. Atau menekankan misi dan menolak pemuridan atau sebaliknya. Misi dan pemuridan merupakan dua unsur penting yang harus ada di dalam pergerakan gereja. Namun, kedua unsur ini seolah "mati suri" di tengah perkembangan zaman.

Gereja diperhadapkan dengan berbagai kompleksitas tantangan, terutama tantangan social, ekonomi dan politik. Persoalan sosial ekonomi membuat gereja hanya berputar pada misi social gereja, yakni memerhatikan orang yang lapar, terpinggirkan, tergusur, bencana alam, dan lain-lain. Bagaimana dengan pemuridan? Pemuridan pun bernasib sama.

Menurut Greg Oden, ${ }^{9}$ bahwa, ketika menghadapi milennium baru, kami mengakui bahwa pertumbuhan gereja saat ini sangatlah dangkal. Semangat kami untuk makin meluas tidak disertai dengan komitmen untuk bertumbuh makin mendalam. Bagaimana mungkin para pemimpin Kristen meratapi degradasi moral yang terjadi dalam masyarakat, padahal ada begitu banyak pribadi yang mengaku memiliki relasi mendalam dengan Yesus Kristus? Jika mereka ialah pengikut Yesus yang sejati, maka gereja tidak akan menutup muka dengan rasa malu pada zaman yang telah berbalik dari Tuhan

Masalahnya terletak pada umat Tuhan yang tidak disiplin, tidak dimuridkan, tidak taat, dan yang mengabaikan firman Tuhan. Bagaimana mungkin para pemimpin Kristen meratapi degradasi moral yang terjadi dalam masyarakat, padahal ada begitu banyak pribadi yang mengaku memiliki relasi mendalam dengan Yesus Kristus? Jika mereka ialah pengikut Yesus yang sejati, maka gereja tidak akan menutup muka dengan rasa malu pada zaman yang telah berbalik dari Tuhan.

9 Greg Ogden, Pemuridan yang Mengubabkan, Jawa Timur: PERKANTAS, 2014 
Masalahnya terletak pada umat Tuhan yang tidak disiplin, tidak dimuridkan, tidak taat, dan yang mengabaikan firman Tuhan.

Persoalan-persoalan sosial yang dihadapi gereja seakan-akan menggiring gereja kepada hanya mencari jalan keluar atas persoalanpersoalan humanitas semata. Gereja harus menyadari hal ini bahwa ia harus taat kepada apa yang katakana Yesus. Yesus sudah mengatakan kepada gereja untuk mandate misi dengan pergi dan menjadikan semua bangsa murid, tetapi ini harus ditaati. J.D. Payne mengatakan bahwa:

'The commission for missionaries to make disciples of all nations begins with calling others to repentance and faith in Jesus. But, it does not end there. This commission also involves teaching these new Kingdom citizens to obey all of Jesus' commands (Mat. 28:20)". ${ }^{10}$

Artinya, gereja tidak hanya tahu bahwa di dalam Alkitab atau Yesus pernah mengatakan bahwa pergi dan jadikan semua bangsa murid melainkan bagaimana mengajar orang untuk menerapkan apa yang telah Yesus perintahkan.

Pada point terakhir ini, penulis memang hanya mengemukakan hubungan misi dengan pemuridan. Namun ketika memahami pentingnya permuridan maka kita tidak hanya berhenti pada pemuridan itu sendiri melainkan dapat melahirkan pemimpin-pemimpin dalam gereja. Jim Putman, ${ }^{11}$ mengatakan bahwa gereja membutuhkan pemimpinpemimpin karena itu gereja harus menerapkan pemuridan untuk melahirkan pemimpin. Alasan Putman hanya sederhana berkaitan dengan pemuridan dan pemimpin yakni, setiap orang percaya yang telah

${ }^{10}$ J.D. Payne, Discipleship in Church Planting: Some Guidelines to Move Us Forward, USA: Good News Publisher, 2011, p. 7

11 Jim, Putman, Building Churches that Make Disciples, Colorado: NavPress, 2010, p. 165-168 
dimuridkan dan dewasa secara rohani maka ia layak untuk dipercayakan tanggungjawab-tanggungjawab rohani.

"I want the process of finding and developing good leaders to be simple and reproducible so that our church can become purposeful and effective at making disciples and leaders... and effective reproducing culture is created when leaders believe in something strongly enough to live out those principles..."12

Bahkan Putman memberikan contoh bahwa dalam pelayanannya di Real Life Ministry, para pemimpin-pemimpin (pastors and missionaries) dapat mengelola gereja karena memiliki kemampuan dan kepribadian yang kuat di dalam Kristus.

Karena itu, discipleship is one who committed to Jesus mission to save people from their sin-God mission is our mission (hand); One who being changed by Christ (heart)-Mat. 7:17-20; One who following chirst (head). ${ }^{13}$ Pemuridan adalah seseorang yang membagikan kehidupannya bagi orang lain yang baru percaya demi menolong mereka untuk mengenal dan memerkenalkan Kristus. Kristus membagikan hidupnya kepada murid-muridNya selam 3,5 tahun. Yesus tidak takut jika gereja tidak maju, bahkan mati. Yesus hanya mengerjakan pemuridan karena pemuridan bersifat reproducible.

Perintah Yesus dalam Matius 7:17-20, "Karena itu pergilah, jadikanlah semua bangsa murid-Ku dan baptislah mereka dalam nama Bapa dan Anak dan Roh Kudus," dan ajarlah mereka melakukan segala sesuatu yang telah Kuperintahkan kepadamu." Sesuai struktur tata bahasa aslinya (Yunani), kalimat induk dalam Amanat Agung adalah "Jadikanlah semua bangsa murid-Ku. "Kata : pergilah... baptislah ... ajarlah merupakan kata kerja yang bergantung pada kata kerja utama jadikanlah ... murid-Ku.

12 Ibid.

${ }^{13}$ Ibid, 32 
Perhatikanlah, berdasarkan Matius 28:19-20, kita mendapati satu amanat,

$$
\begin{gathered}
\text { Jadikanlah semua bangsa ------ kuantitas } \\
\text { Murid-Ku ------ kualitas }
\end{gathered}
$$

dengan tiga tahap,

Baptislah ------ Penginjilan

Ajarlah ------ Pembinaan

Pergilah ------ Pengutusan

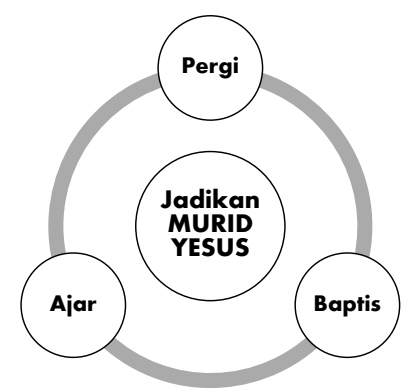

Jika diperhatikan dengan saksama, perintah ini maka kata pergi berada di awal dan berada di akhir, yakni pergilah, baptislah, dan ajarlah, setelah itu harus pergi. Sebab itu, pemuridan memberikan dampak positif. Menurut Herdy Hutabarat, ${ }^{14}$ ada lima dampak positif gereja menerapkan prinsip pemuridan:

1. Menyiapkan dan membangun suatu generasi yang kuat.

2. Menghasilkan Pemimpin-pemimpin Rohani yang dewasa dan berkarakter seperti Kristus.

3. Mengantisipasi Krisis Kepemimpinan.

14 Herdy Hutabarat, Mentoring dan Pemuridan (Bandung: Kalam Hidup, 2014). 
4. Menciptakan proses multiplikasi atau pelipatgandaan

5. Mengalami pertumbuhan baik dalam kesetiaan, kesabaran, ketekunan, keuletan, hati Bapa, hikmat untuk menasehati.

Jika sebaliknya tidak menerapkan pemuridan maka para pemimpin diperhadapkan dengan krisis-krisis kepemimpinan dan krisis pemimpin dalam gereja.

Jadi, sejak di Perjanjian Lama saat Allah memilih Israel dalam kovenan-Nya sebagai umat pilihan-Nya. Allah juga telah menetapkan rencana-Nya di mana Israel tidak hanya menjadi bangsa yang menerima Kanaan sebagai negeri yang dijanjikan dengan berdiam diri melainkan menerima Kanaan dengan tanggungjawab memerkenalkan YHWH kepada bangsa-bangsa yang belum mengenalnya. Tugas ini merupakan inti berita dalam penetapan Israel sebagai umat pilihan.

Keberlanjutan tugas memerkenalkan Allah kepada bangsa-bangsa yang tidak mengenal Allah tidak semata-mata pada Israel (inipun karena kedegilan hati mereka). Penetapan dan pengutusan Israel ke Kanaan hanya merupakan langkah awal Allah dalam rencana-Nya. Sejak kehadiran Kristus di bumi, babak baru tentang tugas terbut pun terkuak. Pelayanan Yesus selama 3,5 tahun merupakan keberlanjutan dari rencana Allah dan bagaimana program Allah dapat berjalan dengan baik, maka Yesus membangun sistem yang berkelanjutan yakni pemuridan yang bersifat reproducible. Dengan menunjuk pada Matius 7:17-20 Yesus memberikan perintah tentang keberlanjutan tugas dan tanggungjawab memerkenalkan Allah kepada bangsa-bangsa lain yang belum mengenal Allah. Tugas tersebut dalam catatan Matius berkesinambung dalam satu tema dengan Kisah Para Rasul 1:8.

Yesus memerkenalkan prinsip pemuridan dan keberlanjutan misi sebagai langkah-langkah dalam membangun dan menciptakan sumber daya manusia untuk tugas dimaksud. Pemuridan kemudian menjadi "jiwa" dari pelayanan Yesus. Sebab selama 3,5 tahun Yesus memberikan 
teladan tentang bagaimana membangun gereja yang kuat dan berkelanjutan yakni "pergilah, baptislah dan ajarlah".

Pemuridan kemudian dilihat oleh beberapa orang pada masa kini sebagai jalan menciptakan pemimpin-pemimpin dalam misi dan pelayanan pastoral. Pemuridan pun kemudian dilihat sebagai jalan keluar atas "tekanan" yang dialami pemimpin-pemimpin gereja, jalan keluar atas krisis-krisis kepemimpinan dan krisis pemimpin. Tetapi mengapa banyak gereja yang meskipun pemuridan merupakan perintah Yesus namun tidak diterapkan? Dan membiarkan pemuridan "mati suri" atau dalam ungkapan Leroy Eims, Pemuridan, Seni yang Hilang.

NOH IBRAHIM BOILIU, memeroleh gelar Sarjana Teologi (S.Th) dari STT Sangkakala, dan Magister Teologi (M.Th) dari STT Berita Hidup Surakarta. Kini sebagai dosen tetap Program Studi Pendidikan Agama Kristen, Fakultas Keguruan dan Ilmu Pendidikan (FKIP), Univ. Kristen Indonesia, Jakarta. Sekarang sedang studi doktoral di STT Cipanas. 